\title{
CONSORCIAÇÃO DE FORRAGEIRAS COM MILHO OUTONAL EM PLANTIO DIRETO: PRODUÇÃO DE GRÃOS E PALHA
}

\author{
Francisco Cezar Belchor Lages Pereira ${ }^{1}$, Veridiana Zocoler de Mendonça ${ }^{2}$, Luiz Malcolm \\ Mano de Mello ${ }^{3}$, Henrique Vinicius de Holanda ${ }^{4}$, Élcio Hiroyoshi Yano ${ }^{3}$ \\ ${ }^{1}$ Engenheiro Agrônomo Msc. Coordenador Comercial Yara Brasil Fertilizantes Dourados (MS). \\ ${ }^{2}$ Engenheira Agrônoma Msc. Doutoranda em Energia na Agricultura UNESP Campus de Botucatu (SP) \\ ${ }^{3}$ Prof. Doutor do DEFERS, UNESP Campus de Ilha Solteira (SP). \\ ${ }^{4}$ Enegenheiro Agrônomo, Mestrando em Produção Vegetal UNESP Campus de Jaboticabal (SP).
}

RESUMO: O consórcio entre culturas graníferas e espécies forrageiras tropicais tem se mostrado eficiente, na formação de pastagem e de palha para o sistema plantio direto. $\mathrm{O}$ presente trabalho foi conduzido com o objetivo de identificar, no sistema de integração agricultura-pecuária, o melhor arranjo de consorciação de milho outonal com quatro forrageiras (Urochloa brizantha, Urochloa ruziziensis, Panicum maximum cv. Tanzânia e Panicum maximum cv. Áries) em três modalidades de semeadura: na linha de semeadura misturado ao adubo do milho, a lanço em área total no mesmo dia da semeadura do milho e a lanço na época de adubação de cobertura do milho e uma testemunha (milho sem consorciação). O delineamento experimental foi em blocos casualizados em esquema fatorial 4x3+1 com quatro repetições. Segundo os resultados para produção de grãos e palha do milho não houve diferenças significativas entre os tratamentos de consorciação e tampouco entre os mesmos e o milho exclusivo. A semeadura das forrageiras na linha do milho proporcionou maior produtividade de matéria seca de palha, porém não houve diferenças entre as espécies estudadas.

Palavras-chave: Competição interespecífica. Semeadura simultânea. Integração lavourapecuária.

\section{INTERCROPPING FORAGE WITH CORN AUTUMNAL IN TILLAGE: PRODUCTION OF GRAIN AND STRAW}

\begin{abstract}
The consortium graníferas between cultures and tropical forage species has been shown effective in the formation of pasture and straw for tillage. This study was conducted with the objective of identifying, in the crop-livestock integration system, the best arrangement of intercropping maize with four autumnal fodder (Urochloa Brizantha, Urochloa ruziziensis, Panicum maximum cv. Tanzania and Panicum maximum cv. Aries) in three methods of sowing: plant line mixed with fertilizer from corn, broadcasted in the same day the corn was sown and broadcasted at the time of manuring of corn and a control (without corn intercropping). The experimental design was a randomized block in factorial $4 \times 3+1$ with four replications. According to the results for the production of grain and maize straw were no significant differences between the treatments of intercropping and intercropping nor between them and the unique corn. The seeding of forage maize in the
\end{abstract}

Cultura Agronômica, Ilha Solteira, v.24, n.1, p.17-26, 2015 
line of highest productivity of dry straw, but there were no differences between the species studied.

Key words: Interspecific competition. Simultaneously planted. Integration crop-livestock.

\section{INTRODUÇÃO}

Na região Oeste do Estado de São Paulo e areas mais baixas do Cerrado, a distribuição irregular das chuvas dificulta a implantação de culturas de outono/inverno, quer seja para grãos, silagem ou para formação de palha para o plantio direto e, segundo Mello et al. (2007), a antecipação da semeadura de uma cultura formadora de palha, de modo a dar-lhe condições de desenvolvimento, e o consórcio de forrageira com milho tem se mostrado como uma alternativa para tal.

A prática da consorciação de culturas produtoras de grãos com forrageiras tropicais, na safra de verão, está sendo utilizada por técnicos e agricultores com intuito de antecipar a implantação da forrageira, principalmente em regiões onde o inverno é seco e não permite bom desenvolvimento de culturas de safrinha. Esse método permite a utilização das forrageiras, tanto para a produção de palha como para a instalação da pastagem Chioderoli et al. (2010).

Segundo Mello et al. (2004) esse sistema integra as duas atividades com os objetivos de maximizar racionalmente o uso da terra, diversificar e verticalizar a produção, minimizar custos e agregar valores aos produtos, pelo aproveitamento dos recursos e benefícios que uma atividade proporciona à outra.

O Sistema Plantio Direto (SPD) e a integração agricultura-pecuária são alternativas de manejo que conciliam a manutenção e, até mesmo, a elevação da produção com maior racionalidade dos insumos empregados Santos et al. (2008).

Portanto, para manter anualmente o aporte de palha exigido para a manutenção da estabilidade do SPD, é de fundamental importância o estabelecimento de culturas para a produção de palha em quantidade adequada à cobertura do solo e que minimize o acelerado processo de decomposição da mesma. Assim, deve-se conhecer a espécie vegetal a ser utilizada no programa de rotação ou consorciação de culturas, quanto à sua produção de massa seca e tempo de decomposição, que interferem diretamente na quantidade de palha sobre o solo.

De acordo com Chioderoli et al. (2010), quando a prioridade principal da consorciação de milho com braquiária for a produtividade de grãos e o foco secundário for a formação de palha, a Urochloa ruziziensis semeada na época de adubação de cobertura do milho proporcionou os maiores valores de produtividade de grãos e quantidade de palha suficiente para a manutenção da estabilidade do SPD.

O objetivo do presente trabalho foi obter informações que contribuam para a tomada de decisão em relação às espécies forrageiras e modalidades de consórcio com milho 
visando à produção grãos e formação de palha.

\section{MATERIAL E MÉTODOS}

O experimento foi conduzido no ano agrícola de 2010/11 na Fazenda de Ensino, Pesquisa e Extensão da UNESP - Campus de Ilha Solteira, em um Latossolo Vermelho Distrófico típico argiloso Embrapa (2006), sob pivô central. O delineamento experimental foi em blocos casualizados com 13 tratamentos em esquema fatorial 4x3+1 e quatro repetições. Cada parcela experimental foi constituída de sete linhas de milho, espaçadas de $0,45 \mathrm{~m}$, com $35 \mathrm{~m}$ de comprimento.

Os tratamentos foram constituídos por quatro forrageiras: Urochloa brizantha, Urochloa ruziziensis; Panicum maximum cv. Tanzânia e Panicum maximum cv. Áries e três modalidades de consórcio das forrageiras com o milho: forrageira na linha de semeadura junto com o adubo do milho, forrageira a lanço em área total no mesmo dia da semeadura do milho, forrageira a lanço na época de adubação de cobertura do milho, no estádio V4 e milho exclusivo.

Para condução e instalação do experimento foram utilizados: Trator de pneus 4x2 TDA, com potência máxima no motor de $77,28 \mathrm{~kW}$, com massa de $5.400 \mathrm{~kg}$ em ordem de marcha; trator de pneus com potência máxima de $54,4 \mathrm{~kW}$ no motor, com massa de 3.951 $\mathrm{kg}$ em ordem de marcha; pulverizador montado , com reservatório de 6001, com barra de 12 m de comprimento, provida de 24 pontas de pulverização tipo leque 110-02, espaçadas por $0,50 \mathrm{~m}$; semeadora-adubadora de precisão de distribuição pneumática de sementes, de arrasto, com depósito de fertilizantes de $940 \mathrm{~kg}$, configurada com disco de corte liso, com sulcador de haste para abertura de sulco de deposição do adubo e discos duplos desencontrados para deposição de sementes e roda compactadora em "V", com sete linhas espaçadas de $0,45 \mathrm{~m}$.

A área experimental estava sendo conduzida em plantio direto há dez anos. A área foi dessecada no dia 10/05/2010 utilizando o herbicida Glyphosate na dose de $1,92 \mathrm{~kg} \mathrm{ha} \mathrm{h}^{-1}$ (i.a.), e a cultura do milho semeada no dia 19/05/2010 visando uma lotação de 60.000 plantas ha ${ }^{-1}$, utilizando-se o híbrido simples DKB 390YG® precoce, com emergência no dia 26/05/2010. As sementes de milho foram tratadas com imidacloprido (i.a) na dose de $34 \mathrm{~g}$ $\mathrm{kg}^{-1}$ semente e tiodicarbe (i.a.) na dose de $113 \mathrm{~g} \mathrm{~kg}^{-1}$ semente. Na consorciação foram utilizados $11 \mathrm{~kg} \mathrm{ha}^{-1}$ sementes certificadas das forrageiras de valor cultural (VC) de $35 \%$. A semeadura das forrageiras misturadas ao adubo do milho e a lanço no dia da semeadura do milho ocorreu no dia 19/05/2010; e a semeadura das forrageiras a lanço na época de cobertura do milho ocorreu no dia 19/06/2010, milho com quatro folhas desenvolvidas.

A adubação de semeadura foi realizada com $300 \mathrm{~kg} \mathrm{ha}^{-1}$ da fórmula comercial 08-2816, a adubação de cobertura foi realizada quando as plantas de milho atingiram o estádio V4, com doses de $72 \mathrm{~kg}$ ha-1 de K2Oe $135 \mathrm{~kg} \mathrm{ha}^{-1}$ de N. Para o controle das plantas daninhas, em 29/06/2010, foi aplicado $1 \mathrm{~kg} \mathrm{ha}^{-1}$ de atrazina (i.a.) e 161,2 $\mathrm{g} \mathrm{ha}^{-1}$ de 2,4-D dimetilamina (i.a). As colheitas do milho e das forrageiras foram realizadas no dia 
24/10/2010. A matéria seca das forrageiras foi avaliada por duas sub-amostras por parcela, coletadas por meio de uma armação de ferro com área de $0,25 \mathrm{~m}^{2}$. O material colhido foi pesado e calculado a matéria verde $\mathrm{em} \mathrm{kg} \mathrm{ha}^{-1}$ e uma amostra foi levada à estufa com circulação forçada de ar, por $72 \mathrm{~h}$ e a $65^{\circ} \mathrm{C}$, determinando-se a massa seca e, posteriormente, calculada a produção de matéria seca ha-1. Para a avaliação da produção de grãos, massa de mil grãos, número de espigas ha-1 e matéria seca de palha do milho, foram colhidas as plantas da área útil de cada parcela (3 linhas de 5,0 m) e submetidas à trilha mecânica. Os grãos foram separados, pesados e os valores corrigidos para a base úmida de $13 \%$. Dos grãos colhidos, foram separadas oito amostras por parcela para a determinação da massa de 1.000 grãos, na base úmida de $13 \%$. Para avaliação de espigas ha $^{-1}$ foram contadas as espigas das três linhas centrais com cinco metros e estimados para ha ${ }^{-1}$. Para avaliação da massa seca de palha do milho, a palha foi pesada para obtenção do peso úmido e uma amostra levada à estufa a $105^{\circ} \mathrm{C}$ por 24 horas para determinação da massa seca. $\mathrm{O}$ valor do peso úmido de palha foi multiplicado pela massa seca para obtenção da produção de matéria seca de palha em $\mathrm{kg} \mathrm{ha}^{-1}$.

Os dados foram submetidos à análise de variância e, quando o valor do teste $\mathrm{F}$ foi significativo realizou-se o teste de Tukey, a $10 \%$ de probabilidade.

\section{RESULTADOS E DISCUSSÃO}

As espécies forrageiras e modalidades de semeadura não influenciaram a produção de grãos e entre estas fontes de variação (Tabela 1). Pariz (2010), em condições semelhantes, obteve valores parecidos com o consórcio das mesmas espécies com milho, resultados que discordam dos obtidos por Mello et al. (2007), que trabalhando com consórcio de B. brizantha e milho, na mesma região e tipo de solo, detectaram a interferência exercida pela forrageira sobre o milho, quando consorciada na linha de semeadura e a lanço em área total, no mesmo dia da semeadura do milho. Em trabalhos semelhantes, Kluthcouski et al. (2000) também verificaram que a produtividade do milho consorciado com a B. brizantha cultivar Marandu, com sementes misturadas ao adubo e distribuídas na linha da cultura, não sofreu redução significativa em relação ao cultivo do milho solteiro, resultados estes observados por vários autores como Freitas et al. (2005); Kluthcouski et al. (2000); Portes et al. (2000); Silva et al. (2004); Pequeno et al. (2006). Observa-se que, independente dos tratamentos, a produtividade de grãos obtida nos consórcios foram condizentes com produtividade média na região do Estado de São Paulo, para o milho irrigado na safra 2009/2010, produção média de 7,5 $\mathrm{t} \mathrm{ha}^{-1}$, de acordo com dados do IEA (2011).

Nas avaliações de massa de 1000 grãos e número de espigas ha ${ }^{-1}$, também não foram constatadas diferenças significativas, evidenciando que os consórcios e as modalidades de semeadura das forrageiras não competiram significativamente com o milho. Borghi \& Crusciol (2007), trabalhando com consórcios de espécies forrageiras com milho encontraram diferenças significativas para essas variáveis. Para matéria seca de palha de milho também não houve diferenças significativas em função dos tratamentos estudados. De modo geral a produção de palha do milho apresenta valores altos e suficientes para a 
manutenção do plantio direto, pois Mello et al. (2007) e Amado (2000) afirmaram que para regiões de clima tropical o aporte anual de palha necessário para manutenção do equilíbrio no SPD deve ser da ordem de $10 \mathrm{tha}^{-1}$.

Tabela 1. Valores médios de produção de grãos, massa de mil grãos, número de espigas ha-1 e matéria seca de palha de milho consorciado com quatro forrageiras em três modalidades de semeadura e milho solteiro. Selvíria - MS, 2010. ${ }^{1}$

\begin{tabular}{cccccc}
\hline \multirow{2}{*}{ Causas de Variação } & $\begin{array}{c}\text { Produção } \\
\text { de grãos } \\
\left(\mathrm{kg} \mathrm{ha}^{-1}\right)\end{array}$ & $\begin{array}{c}\text { Massa de } \\
\text { mil grãos } \\
(\mathrm{g})\end{array}$ & $\begin{array}{c}\text { Número } \\
\text { espigas/ha }\end{array}$ & $\begin{array}{c}\text { Matéria seca } \\
\text { de palha de } \\
\text { milho }\left(\mathrm{kg} \mathrm{ha}^{-1}\right)\end{array}$ \\
\hline \multirow{2}{*}{ Forrageiras (F) } & $\begin{array}{c}\text { B. brizantha } \\
\text { B. ruzizienses }\end{array}$ & 8.415 & 340 & 58.888 & 10.173 \\
& $\begin{array}{c}\text { P. maximum cv. Tanzânia } \\
\text { Testemunha }\end{array}$ & 8.767 & 330 & 58.888 & 10.870 \\
Modalidades de & MFL & 331 & 62.098 & 12.027 \\
semeadura (M) & MFLAS & 8.107 & 329 & 55.925 & 11.393 \\
\hline \multirow{2}{*}{ Valor de F } & MFLAC & 8.089 & 330 & 56.592 & 11.681 \\
& $\mathrm{~F}$ & $0,923^{\mathrm{NS}}$ & $496^{\mathrm{NS}}$ & $1,694^{\mathrm{NS}}$ & $1,86^{\mathrm{NS}}$ \\
\hline CV $(\%)$ & $\mathrm{M}$ & $0,959^{\mathrm{NS}}$ & $242^{\mathrm{NS}}$ & $1,191^{\mathrm{NS}}$ & $1,72^{\mathrm{NS}}$ \\
\hline \multirow{2}{*}{ DMS } & FxM & $0,852^{\mathrm{NS}}$ & $514^{\mathrm{NS}}$ & $0,908^{\mathrm{NS}}$ & $1,76^{\mathrm{NS}}$ \\
\hline & & 16,29 & 6,97 & 11,58 & 16,05 \\
\hline
\end{tabular}

${ }^{1}$ Médias seguidas de mesma letra não diferem entre si pelo teste de Tukey para um nível de $10 \%$ de probabilidade. MFL: Milho com forrageira na linha no mesmo dia de semeadura; MFLAS: Milho com forrageira semeada à lanço no mesmo dia da semeadura do milho; MFLAC: Forrageira semeada à lanço no estádio V4 e Testemunha: Milho exclusivo.

Para a avaliação de matéria seca das forrageiras (Tabela 2), as diferenças significativas ocorreram somente em função das modalidades de semeadura, não apresentando efeito significativo para as diferentes forrageiras. As forrageiras semeadas na linha de semeadura do milho misturadas ao adubo apresentaram maior produção de matéria seca $2575 \mathrm{~kg} \mathrm{ha}^{-1}$ quando comparados esses valores com a produção do tratamento de consorciação de milho com forrageiras a lanço na época de cobertura. A produção de matéria seca de forrageiras semeadas a lanço no dia da semeadura do milho mostrou produção estatisticamente igual às outras modalidades. Esse comportamento do desenvolvimento das forrageiras é devido ao fato de que quando semeadas na linha do milho a planta se apresenta próxima ao fertilizante e, como as sementes foram incorporadas, ocorreu maior germinação e emergência. As forrageiras semeadas na época de adubação de cobertura, decorridos 30 dias da implantação dos outros tratamentos, sofreram o efeito de sombreamento e concorrência do milho, que já havia emergido há 23 dias. Chioderoli (2010) observou valores e comportamento semelhantes para as mesmas modalidades de semeadura, e atribui esses resultados à maior competição por luz, água e nutrientes quando as forrageiras são semeadas após o estabelecimento da cultura do milho.

Cultura Agronômica, Ilha Solteira, v.24, n.1, p.17-26, 2015 
Em estudo de consórcio de braquiária e milho realizado por Freitas et al. (2005), os resultados apontaram menor produção forrageira nos tratamentos em que as forrageiras foram semeadas a lanço 30 dias após a semeadura do milho. Os autores justificam que a falta de incorporação da semente pode ser um fator limitante, pois a incorporação beneficia a germinação e a sobrevivência de plantas, devido à proteção das sementes, à eficiência no aproveitamento da umidade e à facilidade de fixação das plântulas ao solo. Mendonça (2012) em trabalho semelhante encontrou resultados semelhantes, os tratamentos semeados no estádio V4 do milho apresentaram menores produtividades de matéria seca diferindo-se das modalidades na linha e a lanço simultâneo ao milho, este resultado se deve provavelmente ao fato da forrageira semeada na linha e a lanço no mesmo dia da semeadura do milho apresentar 30 dias a mais de ciclo que a forrageira semeada no V4.

Há de se considerar que a avaliação de produção de palha das forrageiras se deu no dia da colheita do milho. As forrageiras em consórcio, por apresentarem menor porte, ficam abafadas e sofrem competição principalmente por luz e é sabido que após a colheita do milho as forrageiras encontram melhores condições de desenvolvimento, fato este relatado por Mendonça (2012) que mostrou um incremento médio de $117 \%$ na produção de palha das forrageiras 60 dias após a colheita do milho consorciado.

Tabela 2. Valores médios de massa seca de quatro de forrageiras consorciadas com milho para grãos, em três modalidades de semeadura. Selvíria - MS, 2010. ${ }^{1}$

\begin{tabular}{ccc}
\hline \multicolumn{2}{c}{ Causas de Variação } & $\begin{array}{c}\text { Massa Seca Forragem } \\
\left(\mathrm{kg} \mathrm{ha}^{-1}\right)\end{array}$ \\
\hline \multirow{2}{*}{ Forrageiras (F) } & B. brizantha & 2.333 \\
& B. ruzizienses & 1.925 \\
& P. maximum cv. Tanzânia & 2.575 \\
P. maximum cv. Áries & 2.208 \\
semeadura (M) & MFL & $2.575 \mathrm{a}$ \\
& MFLAS & $2.162 \mathrm{ab}$ \\
Valor de F & MFLAC & $2.043 \mathrm{~b}$ \\
\hline CV $(\%)$ & F & $1,803^{\mathrm{NS}}$ \\
& $\mathrm{M}$ & $2,554^{*}$ \\
DMS & FxM & $1,393^{\mathrm{NS}}$ \\
\hline & $\mathrm{F}$ & 12,21 \\
\hline & $\mathrm{M}$ & 679 \\
& FxM & 524 \\
\hline
\end{tabular}

${ }^{1}$ Médias seguidas de mesma letra não diferem entre si pelo teste de Tukey para um nível de $10 \%$ de probabilidade. MFL: Milho com forrageira na linha de semeadura no mesmo dia de semeadura; MFLAS: Milho com forrageira semeada à lanço no mesmo dia da semeadura do milho e MFLAC: Forrageira semeadura à lanço no estádio $\mathrm{V}_{4}$.

\section{CONCLUSÕES}

Não houve competição das forrageiras com o milho em relação às produtividades de Cultura Agronômica, Ilha Solteira, v.24, n.1, p.17-26, 2015 
grãos e palha de milho, sendo a produtividade de grãos do milho condizente com a cultura em alta tecnologia para a região.

A produtividade de palha foi suficiente para suprir o aporte anual recomendado para manutenção da estabilidade do plantio direto.

Em áreas de consórcio de milho com forrageiras, quando o foco da atividade for a produção de grãos e de palha, recomenda-se o consórcio com semeadura da forrageira na linha do milho, misturada ao adubo, para otimizar a operação.

\section{REFERÊNCIAS BIBLIOGRÁFICAS}

AMADO, T. J. Manejo da palha, dinâmica da matéria orgânica e ciclagem de nutrientes em plantio direto. In: ENCONTRO NACIONAL DE PLANTIO DIRETO NA PALHA, 7., 2000, Foz do Iguaçu. Resumos... Foz do Iguaçu: F.B.P.D.P., 2000. p.105-111.

BORGHI, E.; CRUSCIOL, C. A. C. Produtividade de milho, espaçamento e modalidade de consorciação com Brachiaria brizantha no sistema plantio direto. Pesquisa Agropecuária Brasileira, Brasília, v. 42, n. 2, p.163-171, 2007.

CHIODEROLI, C. A. Consorciação de braquiárias com milho outonal em sistema plantio direto como cultura antecessora da soja de verão na integração agriculturapecuária. 2010. 84 f. Dissertação (Mestrado em Agronomia) - Faculdade de Engenharia, Universidade Estadual Paulista “Julio de Mesquita Filho", Ilha Solteira, 2010.

CHIODEROLI, C. A.; MELlO, L. M. M.; GRIGOLli, P. J.; SILVA, J. O. R., CESARIN, A. L. Consorciação de braquiárias com milho outonal em plantio direto sob pivô central. Engenharia Agrícola, Jaboticabal, v. 30, n. 6, p.1101-1109, 2010.

EMBRAPA - EMPRESA BRASILEIRA DE PESQUISA AGROPECUÁRIA. Sistema brasileiro de classificação dos solos. 2.ed. Rio de Janeiro: CNPS, 2006. 306 p.

FREITAS, F. C. L.; FERREIRA, L. R.; FERREIRA, F. A.; SANTOS, M. V.; AGNES, E. L.; CARDOSO, A. A.; JAKELAITIS, A. Formação de pastagem via consórcio de Brachiaria brizantha com o milho para silagem no sistema de plantio direto. Planta Daninha, Viçosa, v. 23, n. 1, p.49-58, 2005.

INSTITUTO DE ECONOMIA AGRÍCOLA - IEA. Preços médios mensais recebidos pelos agricultores e área da produção de milho em 2006 à 2010. Disponível em: <http://www.iea.sp.gov.br/out/index.php>. Acesso em: 17 fev. 2011.

KLUTHCOUSKI, J.; COBUCCI, T.; AIDAR, H.; YOKOYAMA, L. P.; OLIVEIRA, I. P. COSTA, J. L. S.; SILVA, J. G.; VILELA, L.; BACELlOS, A. O.; MAGNABOSCO, C. U. Sistema Santa Fé: tecnologia Embrapa: integração lavoura-pecuária pelo consórcio de 
culturas anuais com forrageiras, em áreas de lavoura, nos sistemas direto e convencional. Santo Antonio de Goiás: Embrapa Arroz e Feijão, 2000. 28 p. (Circular técnica, 38).

MELlO, L. M. M.; PANTANO, A. C.; NARIMATSU, K. C. P. Integração agriculturapecuária em plantio direto: consorciação braquiaria e milho. In: CONGRESSO BRASILEIRO DE ENGENHARIA AGRÍCOLA, 36., 2007, Bonito. Anais... Sociedade Brasileira de Engenharia Agrícola, 2007. 1 CD ROM.

MELlO, L. M. M.; YANO, E. H.; NARIMATSU, K. C. P.; TAKAHASHI, C. M.; BORGHI, E. Integração agricultura-pecuária em plantio direto: produção de forragem e resíduo de palha após pastejo. Engenharia Agrícola, Jaboticabal, v. 24, n. 1, p.121-129, 2004.

MENDONÇA, V. Z. Consorciação de milho com forrageiras: Produção de silagem e palha para plantio direto de soja. 2012. 73 f. Dissertação (Mestrado em Agronomia Sistemas de Produção) - Faculdade de Engenharia, Universidade Estadual Paulista, Ilha Solteira, 2012.

NUNES, U. R.; JÚNIOR, V. C. A.; SILVA, E. B.; SANTOS, N. F.; COSTA, H. A. O.;FERREIRA, C. A. Produção de palhada de plantas de cobertura e rendimento do feijão em plantio direto. Pesquisa Agropecuária Brasileira, Brasília, v. 41, n. 6, p.943-948, 2006.

PARIZ, C. M. Desempenhos técnicos e econômicos de um sistema de Integração lavoura-pecuária com a cultura do milho e Adubação nitrogenada de capins dos gêneros Panicum e Brachiaria sob irrigação no cerrado. 2010. 84 f. Dissertação (Mestrado em Agronomia) - Faculdade de Engenharia, Universidade Estadual Paulista "Julio de Mesquita Filho", Ilha Solteira, 2010.

PEQUENO, D. N.; MARTINS, E. P.; AFFERRI, S.; FIDELIS, R. R.; SIQUEIRA, F. L. T.; Efeito da época de semeadura da brachiaria brizantha em consórcio com o milho, sobre caracteres agronômicos da cultura anual e da forrageira em gurupi, estado do Tocantins. Amazônia: Ciência \& Desenvolvimento, Belém, v. 2, n. 3, p.127-133, 2006.

PORTES, T. D. A.; CARVALHO, S. D.; OLIVEIRA, I. D.; KLUTHCOUSKI, J. Análise do crescimento de uma cultivar de braquiária em cultivo solteiro e consorciado com cereais. Pesquisa Agropecuária Brasileira, Brasília, v. 35, n. 7, p.54-57, 2000.

SANTOS, G. G.; SILVEIRA, P. M.; MARCHÃO, R. L.; BECQUER, T.; BALBINO, L. C. Macrofauna edáfica associada a plantas de cobertura em plantio direto em um Latossolo Vermelho do Cerrado. Pesquisa Agropecuária Brasileira, Brasília, v. 43, n. 1, p.115-122, 2008.

Cultura Agronômica, Ilha Solteira, v.24, n.1, p.17-26, 2015 
SILVA, A. A.; JAKELAITIS, A.; FERREIRA, L. R. Manejo de plantas daninhas no sistema integrado agriculturapecuária. In: ZAMBOLIM, L.; FERREIRA, A. A.; AGNES, E. L. (Org.). Manejo integrado: integração agricultura-pecuária. Viçosa: UFV, 2004. p. 117-169.

TIMOSSI, P. C.; DURIGAN, J. C.; LEITE, G. J. Formação de palhada por braquiárias para adoção do sistema plantio direto. Bragantia, Campinas, v. 66, n. 4, p.617-622, 2007. 
